\title{
EDITORIAL
}

\section{Impacto de la mortalidad por cáncer}

\author{
On the impact of cancer mortality
}

\author{
Mónica Bejarano, MD, MSc, MACC \\ Editora, Revista Colombiana de Cirugía \\ Cirujana general, Sección de Cirugía de Trauma y Emergencias, Departamento de Cirugía y Cuidado Intensivo, \\ Fundación Valle del Lili; docente de Cirugía General, Universidad ICESI, Cali, Colombia.
}

El cáncer sigue siendo un problema de salud pública. Es la segunda causa de muerte a nivel mundial después de las enfermedades cardíacas y, según datos de la Organización Mundial de la Salud (OMS), en el año 2015 ocasionó 8,8 millones de defunciones, o sea que casi una de cada seis muertes en el mundo se deben a esta enfermedad. El impacto es mayor en países en desarrollo, donde ocurre cerca del $70 \%$ de todas las muertes por cáncer.

La OMS ha calculado que, en Colombia, el $28 \%$ de las muertes son debidas a enfermedades cardiovasculares, y el segundo lugar lo comparten las muertes por trauma (I7\%) y cáncer (I7\%). La mortalidad prematura, es decir, la probabilidad de morir entre los 30 y los 70 años debido a las cuatro principales enfermedades no transmisibles, es de I2 \%.

Después del incremento en la tasa global de mortalidad por cáncer durante el siglo XX, en su mayoría debido a las muertes por cáncer de pulmón a causa de la epidemia del tabaquismo, es alentador ver una disminución continua en las tasas de mortalidad por cáncer de I, $5 \%$ por año, aproximadamente, desde 1990.
La American Cancer Society, según información recolectada desde 1995 por el National Program of Cancer Registries (NPCR) de los Centers for Disease Control and Prevention (CDC), calculan para 2018 en Estados Unidos, I'735.350 casos nuevos y más de 600.000 muertes por cáncer [I].

En Colombia, la International Agency for Research on Cancer (IARC) era la entidad que estimaba la incidencia y prevalencia de estas enfermedades, apoyada en información estadística del Departamento Administrativo Nacional de Estadística (DANE) y el Registro Poblacional de Cáncer de Cali (RPCC), creado por el Departamento de Patología de la Universidad del Valle en 1962. Desde el año 2005, el Instituto Nacional de Cancerología empezó a generar estimaciones locales en colaboración, además de los anteriores, con los registros poblacionales de Pasto, Manizales y Bucaramanga [2].

Para los años 2007 a 20II, se estimaron 4I.366 casos prevalentes a un año en Colombia (I8.458 en hombres y 22.908 en mujeres) y 29.734 casos nuevos de cáncer por año en hombres y 33.084 en mujeres. Entre los hombres, las localizaciones más prevalentes fueron próstata, colon-recto y

Palabras clave: mortalidad; neoplasias; neoplasias gástricas; neoplasias gastrointestinales; detección precoz del cáncer; investigación.

Key words: mortality; neoplasms; stomach neoplasms; gastrointestinal neoplasms; early detection of cancer; research.

Fecha de recibido: 12/09/2018 - Fecha aceptación: 13/09/2018

Correspondencia: Mónica Bejarano, MD, MSc, MACC

monicirugia@gmail.com

Citar: Bejarano M. Impacto de la mortalidad por cáncer. Rev Colomb Cir. 2018;33:338-9. https://doi.org/10.30944/20117582.79

Este es un artículo de acceso abierto bajo una Licencia Creative Commons - BY-NC-ND https://creativecommons.org/licenses/by-nc-nd/4.0/deed.es 
estómago, mientras en las mujeres, las localizaciones más prevalentes fueron mama, cuello del útero y tiroides. Para el mismo periodo, en Colombia se registraron I6.08I muertes anuales por cáncer en hombres y I6.572 en mujeres. Las principales localizaciones en hombres fueron estómago, próstata, pulmón, colon-recto y leucemias, y en mujeres fueron mama, cuello del útero, estómago, pulmón y colon-recto.

En 2013, la OMS puso en marcha el "Plan de acción mundial para la prevención y el control de las enfermedades no transmisibles, 2013-2020", cuyo objetivo es "reducir en un $25 \%$ la mortalidad prematura causada por el cáncer, las enfermedades cardiovasculares, la diabetes y las enfermedades respiratorias crónicas para el año 2025". Sin embargo, en el mensaje de los copresidentes del $\mathrm{I}^{\circ}$ de junio de $20 \mathrm{I} 8$, refieren que "dado que muchos compromisos políticos no se están cumpliendo, los países no están en condiciones de alcanzar esta meta. Las medidas nacionales contra las enfermedades no transmisibles son, en el mejor de los casos, desiguales. Las inversiones nacionales siguen siendo deplorablemente pequeñas, y no se están movilizando fondos suficientes a escala internacional" [3].

Es necesario tener en mente que la prevalencia, el diagnóstico, el tratamiento y la supervivencia en casos de cáncer, varían considerablemente dependiendo de un sinnúmero de factores, entre los que se cuentan la ubicación geográfica, la raza, el sexo, las inequidades económicas, la exposición a factores de riesgo y las barreras de acceso a los sistemas de salud de alta calidad. Además, un $30 \%$ de las muertes por cáncer se deben a cinco factores de riesgo comportamentales y alimentarios (índice de masa corporal elevado, consumo insuficiente de frutas y verduras, falta de actividad física, consumo de tabaco y consumo de alcohol) y, entonces, podrían prevenirse.

Cerca de $15 \%$ de los casos de cáncer diagnosticados en 2012 se atribuyeron a infecciones, especialmente las causadas por Helicobacter pylori, los papilomavirus humanos, los virus de la hepatitis B y de la hepatitis C, y el virus de Epstein-Barr [4]. Entonces, podríamos decir que entre el 30 y el 50 $\%$ de los cánceres se pueden evitar si se disminuye la exposición a los factores de riesgo y se aplican estrategias preventivas con base científica, $y$ que, si el cáncer se diagnostica tempranamente, es más probable que el tratamiento sea eficaz, reduciendo su mortalidad.

La Asociación Colombiana de Cirugía, de acuerdo con su misión en el inmediato futuro, donde "impulsará prioritariamente el desarrollo científico y gremial de los cirujanos de Colombia, fortalecerá su condición de ente integrador de los intereses de sus asociados y vigorizará su presencia en el país", apoya la investigación y es por ello que en este número de la Revista presentamos el proyecto Urkunina 5000. Este es una investigación de la prevalencia de lesiones precursoras de malignidad gástrica y del efecto de la erradicación de la infección por $H$. pylori como prevención primaria del cáncer gástrico, llevada a cabo en el departamento de Nariño, para información de nuestros lectores, con el deseo de que sus resultados ayuden a disminuir el impacto de esta enfermedad en nuestro país.

\section{Referencias}

I. Siegel R, Miller K, Jemal A. Cancer Statistics, 20I8. Ca Cancer J Clin. 2018;68:7-30. doi: I0.3322/caac.21442.

2. Pardo C, Cendales R. Incidencia, mortalidad y prevalencia de cáncer en Colombia, 2007-20II. Primera edición. Bogotá: Instituto Nacional de Cancerología; 2015. p. 148.

3. Organización Mundial de la Salud. Es hora de actuar: informe de la Comisión independiente de alto nivel de la OMS sobre enfermedades no transmisibles. Ginebra: Organización Mundial de la Salud; 20I8. Licencia: CC BY-NC-SA 3.0 IGO. Fecha de consulta: 3I de agosto de 20I8. Disponible en: hp://www.who.int/ iris/handle/I0627I2

4. Plummer M, de Martel C, Vignat J, Ferlay J, Bray F, Franceschi S. Global burden of cancers attributable to infections in 2012: A synthetic analysis. Lancet Glob Health. 20I6;4:e609-I6. doi: I0.IOI6/S22I4-IO9X(I6)30I43-7 